(500 IU) compared with $300 \mu \mathrm{g}$ used in the Canadian work. ${ }^{3}$

Widespread administration of anti-D immunoglobulin antenatally in this regimen would not be possible at present because of limited supply from a decreasing pool of immunised donors. Immunoglobulin produced by genetic engineering, however, may be available soon, and trials are planned to study the effectiveness of even lower doses.

When studying a treatment regimen for any side effects it is important to avoid the bias created by considering only untoward consequences. Unexpected benefits are also possible, and we paid particular attention to any effects anti-D immunoglobulin may have had on the incidence of hypertensive disease such as pre-eclampsia. Some evidence suggests that previous blood transfusions may reduce the incidence, ${ }^{15}$ and possibly some blood products also do so. The data collected, however, though not contradicting this hypothesis, showed no significant difference.

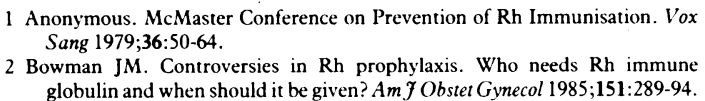

3 Bowman JM, Chown B, Lewis M, Pollock JM. Rh isoimmunization during pregnancy: antenatal prophylaxis. Can Med Assoc $\mathcal{F}$ 1978;118:623-7.

4 Tovey LAD. Haemolytic disease of the newborn - the changing scene. $\mathrm{Br} \mathcal{f}$ Obstet Gynaecol 1986;93:960-6.

5 Blajchman M, Zipursky A, Bartsch FR, Hermann M, Eklund J, Nevanilinna HR. Rh immunization during pregnancy. Vox Sang 1979;36:50-64.

6 Tovey LAD, Townley A, Stevenson BJ, Taverner J. The Yorkshire antenatal anti-D immunoglobulin trial in primigravidae. Lancet 1983 ;ii:244-6.

7 Nusbacher J, Bove JR. Rh Immunoprophylaxis: is antepartum therapy desirable? N Engl f Med 1980;303:935-7.

8 Tovey GH. Should anti-D immunoglobulin be given antenatally? Lancet 1980;ii:466-8.

9 Adams MM, Marks JS, Kaplan JP. Cost implications of routine antenatal administration of Rh immune globulin. Am 7 Obstet Gynecol 1984;149. 633-8.

10 Hensleigh PA. Preventing rhesus isoimmunization. Antepartum Rh immun globulin prophylaxis versus a sensitive test for risk identification. $A m \mathcal{J}$ Obstet Gynecol 1983;146:749-55.

11 Torrance GW, Zipursky A. Cost-effectiveness of antepartum prevention of Rh immunisation. Clin Perinatol 1984;11:267-81.

12 Hensleigh PA. Controversies in Rh prophylaxis. Am $\mathrm{f}$ Obstet Gynecol 1985;153:112.

13 Bowman JM. Controversies in Rh prophylaxis. Am f Obstet Gynecol 1985; 153: 112-3.

14 Tabsch KMA, Lebherz TB, Crandall BF. Risks of prophylactic anti-D immunoglobulin after second-trimester amniocentesis. Am $\mathcal{f}$ Obstet Gynecol 1984;149:225-6.

15 Feeney JG, Tovey LAD, Scott JS. Influence of previous blood-transfusion on incidence of pre-eclampsia. Lancet 1977;i:874-5.

16 Perrault RA. Hogman CF. Low concentration red cell antibodies. III. Cold IgG anti $\mathrm{D}$ in pregnancy, incidence and significance. Acta Universitates Upsaliensis 1972;120:5.

(Accepted 10 April 1989)

\title{
Damp housing, mould growth, and symptomatic health state
}

\author{
Stephen D Platt, Claudia J Martin, Sonja M Hunt, Chris W Lewis
}

Medical Research Council Unit for Epidemiological Studies in Psychiatry, Royal Edinburgh Hospital, Edinburgh EH10 5HF Stephen D Platt, PHD, research sociologist

\section{Research Unit in Health} and Behavioural Change, University of Edinburgh, Edinburgh EH1 2QZ

Claudia J Martin, PHD research fellow

Sonja M Hunt, PHD, senior research fellow

\section{Division of Applied}

Microbiology, Department of Bioscience and

Biotechnology, University of Strathclyde, Glasgow G1 1XQ

Chris W Lewis, PHD, research fellow

Correspondence to: $\mathrm{Dr}$ Platt.

\section{Abstract}

Objective-To examine the relation between damp and mould growth and symptomatic ill health.

Design-Cross-sectional study of random sample of households containing children; separate and independent assessments of housing conditions (by surveyor) and health (structured interview by trained researcher).

Setting-Subjects' homes (in selected areas of public housing in Glasgow, Edinburgh, and London).

Subjects-Adult respondents ( $94 \%$ women) and 1169 children living in 597 households.

End points-Specific health symptoms and general evaluation of health among respondents and children over two weeks before interview; and score on general health questionnaire (only respondents).

Measurements and main results-Damp was found in $184(30.8 \%)$ dwellings and actual mould growth in $274(45.9 \%)$. Adult respondents living in damp and mouldy dwellings were likely to report more symptoms overall, including nausea and vomiting, blocked nose, breathlessness, backache, fainting, and bad nerves, than respondents in dry dwellings. Children living in damp and mouldy dwellings had a greater prevalence of respiratory symptoms (wheeze, sore throat, runny nose) and headaches and fever compared with those living in dry dwellings. The mean number of symptoms was higher in damp and mouldy houses and positively associated with increasing severity of dampness and mould (dose response relation). All these differences persisted after controlling for possible confounding factors such as household income, cigarette smoking, unemployment, and overcrowding. Other possible sources of bias that might invalidate the assumption of a causal link between housing conditions and ill health-namely, investigator bias, respondent bias, and selection bias - were also considered and ruled out.

Conclusion-Damp and mouldy living conditions have an adverse effect on symptomatic health, particularly among children.

\section{Introduction}

Showing a direct relation between damp housing and ill health is by no means straightforward. Firstly, those living in the worst housing conditions are likely to be experiencing other forms of adversity, such as low income and unemployment. Secondly, personal behaviour may also play a part in the causation of ill health. An equally important methodological concern is the process of the data collection itself. If information about health and housing conditions is elicited in the same interview respondents may exaggerate the prevalence of problems, leading to a spurious association between the two phenomena. Moreover, the researchers themselves may influence reporting.

In 1986 we carried out a preliminary study in Edinburgh, which attempted to overcome these methodological difficulties by using a double blind research design. ${ }^{1}$ Children living in damp houses, particularly where there was also mould growth, were reported to have higher rates of respiratory and gastrointestinal symptoms, aches and pains, and fever than children in dry dwellings. These differences could not be attributed to smoking or differences between damp and dry households regarding unemployment, income, overcrowding, or duration of tenancy. The numbers of households that included a child was not large enough $(n=101)$, however, to permit a full analysis of the role of other possible confounding variables. Accordingly, we carried out a larger scale, more detailed investigation.

\section{Subjects and methods}

The study was conducted in three major cities: Edinburgh, Glasgow, and London. Within each city discrete geographical areas of public housing were 
identified in which $(a)$ families with young children predominated; $(b)$ the prevalence of damp housing was thought to be in the range of $25-50 \%$ of total dwellings; (c) socioeconomic state was likely to be fairly homogeneous; and $(d)$ types of housing and structures of buildings, including any renovations, could be clearly specified. Two sites were chosen in Edinburgh, two in Glasgow, and one in London. Tenants' groups were contacted and their cooperation elicited. Lists of addresses at the chosen sites were obtained from the relevant housing departments. The intention was to achieve a sample of 500 eligible households in Edinburgh and in Glasgow and 200 in London. A random sample of addresses was drawn according to the total number of dwellings in the area.

Only those households with at least one child aged under 16 were eligible for inclusion in the study. As official statistics on the exact location of families with young children were not available the sample was identified in two ways: $(a)$ at the time of the main health interview (see below) the interviewers identified suitable families by contacting each dwelling on the list; and $(b)$ in two of the sites members of the tenants' association identified addresses on the list containing families who met the study criteria.

Two surveyors carried out an assessment of dampness (severity and type) and mould (severity and location) and details of the structure of the dwelling. Using an air sampler (Surface Air Systems) they extracted air samples from rooms and, where visible mould growth was present, a sample from each affected room was collected. A microbiologist estimated spore counts from the air samples and identified the fungi from air and walls when possible.

We devised and pretested two survey forms. The form for the house conditions survey contained items on type of building, location, number of rooms, dampness, mould, ventilation, insulation, and renovations. The health survey was a revised version of that used by Martin et al. ${ }^{1}$ In the course of a structured interview the respondent (whenever possible the female householder) answered detailed questions about her own and her children's health during the past two weeks; smoking by all adults and children; type of heating, washing, and drying facilities; presence of pets; economic activity and occupation of all adults in the household; household income; and housing conditions and facilities.

The study was carried out during February-April 1988. Once the health interview had been completed the surveyors were instructed to visit the dwelling. The petri dishes containing air and wall mould samples were taken each day to the University of Strathclyde, where they were refrigerated and cultured. Air spore counts were calculated and fungi identified when possible. The surveyors and the microbiologist were blind to each other's findings and also to the findings of the health survey team.

We used four categorical independent variables relating to housing conditions. Households that received a house conditions survey were classified into three groups: those where there was no objective evidence of dampness or mould growth (dry), those with only damp, and those with mould (whether or not dampness was also present). The overall dampness in the household was calculated by averaging the score for each bedroom, sitting room, and kitchen on a four point scale of severity ( $0=$ none; $3=$ severe). Households in which the average dampness score exceeded zero (no dampness whatsoever) were divided into three approximately equal sized groups labelled mild (score ranging between 0.01 and 0.52$)$, moderate $(0.53$ to $1 \cdot 05)$, and severe $(\geqslant 1 \cdot 06)$. A similar procedure was adopted to divide households into four groups differing in average severity of mould (none, mild $(0.01$ to
$0 \cdot 45)$, moderate $(0.46$ to $0 \cdot 77)$, and severe $(\geqslant 0 \cdot 78))$.

The spore concentration per $\mathrm{m}^{3}$ air was measured in the kitchen, living room, and bedrooms of households in Edinburgh and Glasgow visited by the surveyors. On the basis of preliminary work in Edinburgh (B Flanagan and C A Hunter, unpublished data) and elsewhere ${ }^{2-4}$ we devised a five point scale (coded 1 to 5): low ( $\leqslant 100$ viable spores $/ \mathrm{m}^{3}$ air), medium (101-300), high (301-1000), very high (1001-5000), and extremely high $(>5000)$. The household spore concentration was the mean score on the scale per available room. A new variable was created by dividing this mean score into three groups: low (scoring 1), medium (1.01 to $2 \cdot 00$ ), and high $(>2)$.

To ensure that the relation between housing conditions and ill health was not invalidated by covariation with other variables several possible confounding factors were also examined, particularly cigarette smoking in the household (no/yes), respondents' cigarette smoking (no/yes), net household income (above median (£80)/below median), overcrowding (less than/ more than 1.5 people per room), employment in the household (somebody employed/nobody employed), and employment state of the respondent (employed/ unemployed, no paid employment).

The respondent was asked to report on the presence of 16 specific symptoms seen in the past two weeks in any child (aged 0-15) living in the household. We devised two summary symptom scores relating to children: the unadjusted score being the total number of symptoms among all children in the household and the adjusted score being the total of symptoms divided by the number of children - that is, the mean number of symptoms per child. Another summary dependent variable for children was the mean score on health evaluation derived from the respondent's general evaluation of each child on a scale of 1 (excellent) to 5 (very poor). The respondent was also asked to report whether she had suffered from any of 17 specific symptoms over the past fortnight. A summary symptom score was merely the sum of individual symptoms. In addition, the respondent was asked to rate her general health on the same five point scale used for children and to complete the 30 item general health questionnaire $^{5}$ (range $0-30$ ), here used as a general indicator of psychological distress. Finally, we inquired about medical treatment for symptoms and the presence of a recurrent or longstanding illness among both respondents and children.

Univariate analyses of the relation between each independent variable and dependent variables were carried out with $\chi^{2}$ tests (categorical variables) or one way analysis of variance (metric variables). Subsequently, multivariate analyses were performed to examine the association between housing conditions and ill health after controlling for possible confounding factors. When the response variable was binary/ categorical we used logistic linear regression analysis ${ }^{6}$; for metric response variables we used analysis of covariance. ${ }^{7}$ The extent of any dose-response relation between severity of dampness, mould growth, and air spore concentration and health was assessed by means of tau c (categorical variables) and the Pearson correlation coefficient (metric variables). Identical results were obtained with respect to metric variables transformed to base 10 logarithms. Only original values are reported below.

On the basis of previous work we expected to find a distinct effect of adverse housing conditions on respiratory and gastrointestinal symptoms in children and on emotional distress in adults. Evidence of a dose response relation was considered to be particularly relevant in assessing the likelihood of a causal impact of dampness and mould on symptomatic health.

For the purposes of this report the results from 
Edinburgh, Glasgow, and London have been combined. (Although the prevalence of damp and mould varied in each city, there were no pronounced differences in the association between housing conditions and symptomatic health state between cities.)

\section{Results}

\section{RATES OF RESPONSE}

Of 1220 households with children eligible for inclusion in the study, a health interview was secured in 891 $(73.0 \%) ; 156(12.8 \%)$ respondents refused to be interviewed, and $173(14 \cdot 2 \%)$ could not be contacted. Surveyors completed their investigations of housing conditions in 597 households, constituting $48.9 \%$ of eligible households and $67 \cdot 0 \%$ of those who had the health interview. A comparison between surveyed $(\mathrm{n}=597)$ and non-surveyed $(\mathrm{n}=294)$ households showed no differences in sociodemographic characteristics, such as gender, marital state, household size (including number of children), social class, and overcrowding, or regarding disposable income, cigarette smoking, length of time at current address, presence of pets, or self-reported damp or mould. The only significant difference concerned employment: $131(22 \%)$ respondents in surveyed households were employed compared with $100(34 \%)$ respondents in non-surveyed households $\left(\chi^{2}=12 \cdot 54, \mathrm{df}=1, \mathrm{p}<0 \cdot 001\right)$; corresponding figures for any adult in employment were $257(43 \%)$ and $156(53 \%)$, respectively $\left(\chi^{2}=7 \cdot 55\right.$, $\mathrm{df}=1, \mathrm{p}<0.01)$

All subsequent analyses were based on the 597 households, containing 1169 children, that received both a housing survey and a health interview.

COMPARISON OF THREE HOUSING CONDITIONS GROUPS

Out of the 597 households, only $184(30.8 \%)$ were free from damp or mould (dry). In $139(23.3 \%)$ households surveyors found evidence of damp and in $274(45 \cdot 9 \%$, of which all but nine were also damp) actual mould growth was visible. The three housing conditions groups (dry, only damp, mouldy) were compared for descriptive purposes on a number of background (sociodemographic and other) variables. (It was, of course, recognised that a variable could act as a confounder even if it did not differentiate significantly between groups.) Only one significant difference emerged: respondents living in dry households had been living an average of 5.9 (SD 4.9 ) years at the address compared with $4 \cdot 8(4 \cdot 1)$ years among respondents in damp houses and $6 \cdot 4(5 \cdot 5)$ years among

TABLE I-Respondent's health during past two weeks by housing conditions. Figures are number (percentages) unless stated otherwise

\begin{tabular}{|c|c|c|c|c|c|c|}
\hline \multirow[b]{2}{*}{ Symptom. } & \multicolumn{3}{|c|}{ Housing conditions } & \multicolumn{3}{|c|}{ Significance } \\
\hline & $\begin{array}{l}\text { No damp } \\
\text { or mould } \\
(\mathrm{n}=184)\end{array}$ & $\begin{array}{l}\text { Damp only } \\
(\mathrm{n}=139)\end{array}$ & $\begin{array}{l}\text { Mould } \\
(\mathrm{n}=274)\end{array}$ & $\gamma:$ & $\begin{array}{l}\text { Degrees } \\
\text { of } \\
\text { freedom }\end{array}$ & $\begin{array}{c}\mathrm{p} \\
\text { Value }\end{array}$ \\
\hline Tiredness & $76(+1 \cdot 3)$ & $69(50 \cdot 0)$ & $141(51 \cdot 5)$ & 4.84 & 2 & 0.089 \\
\hline High blood pressure & $9(4 \cdot 9)$ & $7(5 \cdot 1)$ & $22(8 \cdot 0)$ & $2 \cdot 33$ & 2 & 0.312 \\
\hline Persistent cough & $30(16 \cdot 3)$ & $27(19 \cdot 4)$ & $64(23 \cdot 4)$ & $3 \cdot 47$ & 2 & $0 \cdot 177$ \\
\hline Bad nerves & $35(19 \cdot 0)$ & $31(22 \cdot 3)$ & $80(29 \cdot 2)$ & $6 \cdot 62$ & 2 & 0.036 \\
\hline Wheezing & $19(10 \cdot 3)$ & $17(12 \cdot 2)$ & $37(13 \cdot 6)$ & $1 \cdot 07$ & 2 & 0.587 \\
\hline Aching joints & $28(15 \cdot 2)$ & $23(16 \cdot 5)$ & $65(23 \cdot 7)$ & 6.05 & 2 & 0.049 \\
\hline Skin problems & $26(1+1)$ & $23(16 \cdot 5)$ & $43(15 \cdot 7)$ & $0 \cdot 39$ & 2 & 0.825 \\
\hline Persistent headaches & $49(26 \cdot 6)$ & $43(30 \cdot 9)$ & $75(27 \cdot 4)$ & 0.82 & 2 & 0.664 \\
\hline Nausea-vomiting & $7(3 \cdot 8)$ & $9(6 \cdot 5)$ & $27(9 \cdot 9)$ & $6 \cdot 17$ & 2 & $0 \cdot 046$ \\
\hline Backache & $41(22 \cdot 3)$ & $48(34 \cdot 5)$ & $81(29 \cdot 6)$ & $6 \cdot 13$ & 2 & 0.047 \\
\hline Blocked nose & $25(13 \cdot 6)$ & $18(12 \cdot 9)$ & $58(21 \cdot 2)$ & 6.53 & 2 & 0.038 \\
\hline Palpitations & $8(4 \cdot 3)$ & $9(6 \cdot 5)$ & $22(8 \cdot 0)$ & $2 \cdot 44$ & 2 & 0.295 \\
\hline Fainting spells & $3(1 \cdot 6)$ & $12(8 \cdot 6)$ & $17(6 \cdot 2)$ & $8 \cdot 37$ & 2 & 0.015 \\
\hline Diarrhoea & $5(2 \cdot 7)$ & $9(6 \cdot 5)$ & $19(6 \cdot 9)$ & $4 \cdot 06$ & 2 & 0.131 \\
\hline Constipation & $11(6.0)$ & $8(5 \cdot 8)$ & $33(12 \cdot 0)$ & $7 \cdot 08$ & 2 & 0.029 \\
\hline Breathlessness & $19(10 \cdot 3)$ & $24(17 \cdot 3)$ & $51(18 \cdot 6)$ & 6.01 & 2 & 0.049 \\
\hline Feeling depressed & $51(27 \cdot 7)$ & $47(33 \cdot 8)$ & $104(38 \cdot 0)$ & $5 \cdot 15$ & 2 & 0.076 \\
\hline Any symptom & $144(78 \cdot 3)$ & $113(81 \cdot 3)$ & $217(79 \cdot 2)$ & 0.46 & 2 & 0.795 \\
\hline Mean (SD) No of symptor & $2 \cdot 40(2 \cdot 37)$ & $3.05(3 \cdot 01)$ & $3.43(3.25)$ & $F=6.67$ & 2,594 & 0.001 \\
\hline Mean (SD) health evaluation score & $2 \cdot 41(0.93)$ & $2 \cdot 49(0.99)$ & $2.66(0.97)$ & $F=4.09$ & 2,594 & 0.017 \\
\hline Mean (SD) general health questionnaire score & $5 \cdot 74(7 \cdot 12)$ & $6 \cdot 87(7 \cdot 78)$ & $7 \cdot 20(8 \cdot 35)$ & $\mathrm{F}=1.92$ & 2,583 & $0 \cdot 148$ \\
\hline
\end{tabular}

respondents in mouldy houses $(\mathrm{F}=4 \cdot 35, \mathrm{df}=2,584$, $\mathrm{p}<0.02)$; only the difference between damp and mouldy houses was significant (Scheffe test, $\mathrm{p}<0.05$ ). Housing groups did not differ in number of children (mean (SD) 2.0 (1.0)), total number of household members $(3 \cdot 8(1 \cdot 2))$, respondent's gender $(559(93 \cdot 6 \%)$ women), respondent's marital state (384 (64.3\%) married), net household income $(293(49 \cdot 0 \%)$ under $£ 80$ per week), respondent's smoking $(415,(69 \cdot 5 \%))$, any smoker in household $(476(79 \cdot 7 \%))$, respondent employed (136 $(22 \cdot 8 \%)$ ), any household member employed $(259(43 \cdot 4 \%))$, overcrowding $(109(18 \cdot 3 \%))$, presence of pets $(269(45 \cdot 1 \%))$, tenure of last house (465 (77.9\%) council dwelling), reasons for moving from last dwelling ( $90(15.0 \%)$ because of dampness; $247(41.4 \%)$ because of other problems with the house; $26(4.3 \%)$ for health reasons), and use of Calor gas heating $(81(13 \cdot 5 \%))$. Respondents in mouldy households, however, reported more problems apart from the damp (especially noise, poor repair, and cold) than respondents in damp or dry households. (Mean (SD) problems $2.7(1.5), 2.5(1.6)$, and $2 \cdot 2(1.6)$, respectively; $F=5 \cdot 0, d f=2,594, p<0 \cdot 01)$. In particular, the prevalence of cold as a problem was reported in $222(81 \%), 100(72 \%)$, and $114(62 \%)$ households, respectively; $\left.\chi^{2}=20 \cdot 4, \mathrm{df}=2, \mathrm{p}<0.001\right)$.

\section{HOUSING CONDITIONS AND RESPONDENT'S HEALTH}

Table I shows the relation between prevalence of symptoms in the respondent and housing conditions. Significant differences between groups were found regarding bad nerves, aching joints, nausea and vomiting, backache, blocked nose, fainting spells, constipation, and breathlessness. The lowest proportion reporting symptoms was found in dry households; with only one exception (fainting spells) the highest proportion was found in mouldy households. Although housing conditions were unrelated to the presence of any particular symptom, there was a significant variation in the total number of symptoms and in the respondent's evaluation of her health. In particular, those living in mouldy houses scored significantly higher than those living in dry conditions (Scheffe test, $\mathrm{p}<0.05$ ). The general health questionnaire score was not related to housing conditions (table I).

Preliminary univariate analyses had shown that only two of the possible confounding variables (respondent's economic position and cigarette smoking) were significantly associated with the presence or absence of individual symptoms. We therefore undertook a series of logistic regression analyses in which the dependent variables were the eight symptoms previously shown to be significantly associated with housing conditions. After controlling for the respondent's economic position and cigarette smoking these differences remained significant for all eight dependent symptom variables (problem free households always having the lowest proportion of respondents positive for symptoms).

The relation between housing conditions on the one hand and the total number of symptoms, health evaluation score, and general health questionnaire score on the other was further examined by means of analyses of covariance. After we controlled for length of time at address, other housing problems (or cold alone), respondent's economic position, respondent's cigarette smoking, and household income housing conditions remained significantly associated with the total number of symptoms ( 6 ranging between $0 \cdot 10$ and $0.14, \mathrm{p}<0.05$ to $<0.005$ ), with those living in mouldy households reporting most and those in dry households fewest symptoms. Housing conditions were not significantly associated with health evaluation score after we controlled for other possible con- 
founding variables, and the relation with the general health questionnaire score remained non-significant.

We examined the dose-response relation between the respondents' symptoms and increasing severity of dampness, mould growth, and air spore concentration. Table II summarises the findings of these analyses.

TABLE II - Respondent's health during past two weeks. Dose-response relation with damp, mould, and air spore count. Figures are tau $c$ values ( $p$ values) unless stated otherwise

\begin{tabular}{|c|c|c|c|}
\hline Symptom & $\begin{array}{c}\text { Dampness } \\
(\operatorname{Max} \mathbf{n}=597) \\
\end{array}$ & $\begin{array}{l}\text { Mould growth } \\
(\operatorname{Max} \mathrm{n}=589)\end{array}$ & $\begin{array}{c}\text { Air spore count } \\
(\operatorname{Max} n=485)\end{array}$ \\
\hline Tirednc & $0.09(0.028)$ & $0.06(0.076)$ & $-0.02(0.341)$ \\
\hline High blood pressure & $0.04(0.024)$ & $0.04(0.027)$ & $0.05(0.017)$ \\
\hline Persistent cough & $0.09(0.010)$ & $0 \cdot 04(0 \cdot 110)$ & $0.06(0.062)$ \\
\hline Bad nerves & $0.07(0.036)$ & $0.09(0.008)$ & $0.08(0.031)$ \\
\hline Wheezing & $0.05(0.047)$ & $0.03(0.125)$ & $0.01(0.413)$ \\
\hline Aching joints & .080) & 22) & $0.06(0.083)$ \\
\hline Skin problems & $0.03(0.209)$ & & \\
\hline laches & 0.04 & $-0.02(0.279)$ & $-0.11(0.006)$ \\
\hline $\mathrm{Nat}$ & & 0.05 & $0.02(0.230)$ \\
\hline Back & 167) & 0.02 & $0.11(0.009)$ \\
\hline Bloc & & & -451) \\
\hline Palpi & 6) & 0.03 & $0.08(0.001)$ \\
\hline Fainting spells & 013) & .381) & $-0.01(0.289)$ \\
\hline Diarrhoea & 146) & 0.02 & $-0.01(0.413)$ \\
\hline Const & 1) & 0.04 & $0.01(0.414)$ \\
\hline Breathlessnes & $0.09(0.003)$ & $0.05(0.057)$ & $0.08(0.019)$ \\
\hline Feeli & 1) & $0.08(0.026)$ & $0.06(0.107)$ \\
\hline Any symptom & $0.02(0 \cdot 319)$ & $-0.02(0.299)$ & $0.00(0.482)$ \\
\hline \multirow{3}{*}{$\begin{array}{l}\text { No of symptoms } \\
\text { Health evaluation score } \\
\text { General health } \\
\quad \text { questionnaire }\end{array}$} & $=0$. & $r=0$. & $\mathrm{r}=0.0$ \\
\hline & $\mathrm{r}=0.07(0.047)$ & & \\
\hline & $r=0.06(0.082)$ & $\mathrm{r}=0.06(0.086)$ & $\mathrm{r}=0.01(0.41$ \\
\hline
\end{tabular}

There was a significant tendency for increasing severity of dampness to be associated with a greater prevalence of the following symptoms: tiredness, high blood pressure, persistent cough, bad nerves, wheezing, nausea and vomiting, blocked nose, fainting spells, and breathlessness. The greater the extent of mould growth the higher the proportion of respondents reporting high blood pressure, bad nerves, aching joints, nausea and vomiting, blocked nose, and feeling depressed. Finally, the concentration of the air spores was positively associated with high blood pressure, bad nerves, backache, palpitations, and breathlessness and negatively associated with persistent headaches. Overall, the total number of symptoms tended to increase with higher degrees of dampness and mould and air spore concentration, while the health evaluation score was related only to severity of dampness and mould growth. No dose-response effect on the general health questionnaire score was evident.

Respondents living in the three different housing conditions were compared regarding action taken

TABLE III-Children's health during past two weeks by housing conditions. Figures are number (percentages) unless stated otherwise

\begin{tabular}{|c|c|c|c|c|c|c|}
\hline \multirow[b]{2}{*}{ Symptom^ } & \multicolumn{3}{|c|}{ Housing conditions } & \multicolumn{3}{|c|}{ Significance } \\
\hline & $\begin{array}{l}\text { No damp } \\
\text { or mould } \\
(n=184)\end{array}$ & $\begin{array}{c}\text { Damp } \\
\text { only } \\
(n=139)\end{array}$ & $\begin{array}{c}\text { Mould } \\
(n=274)\end{array}$ & $\chi^{2}$ & $\begin{array}{c}\text { Degrees } \\
\text { of } \\
\text { freedom }\end{array}$ & $\begin{array}{c}\mathrm{p} \\
\text { Value }\end{array}$ \\
\hline Bodily aches-pains & $23(12 \cdot 5)$ & $30(21 \cdot 6)$ & $43(15 \cdot 7)$ & 4.90 & 2 & 0.086 \\
\hline Diarrhoea & $34(18 \cdot 5)$ & $30(21 \cdot 6)$ & $50(18 \cdot 2)$ & 0.73 & 2 & 0.694 \\
\hline Wheezing & $30(16 \cdot 3)$ & $26(18 \cdot 7)$ & $74(27 \cdot 0)$ & $8 \cdot 41$ & 2 & 0.015 \\
\hline Vomiting & $22(12 \cdot 0)$ & $25(18 \cdot 0)$ & $52(19 \cdot 0)$ & $4 \cdot 18$ & 2 & $0 \cdot 124$ \\
\hline Sore throat & $56(30 \cdot 4)$ & $34(24 \cdot 5)$ & $116(42 \cdot 3)$ & 14.99 & 2 & $<0.001$ \\
\hline Irritability & $23(12 \cdot 5)$ & $28(20 \cdot 1)$ & $56(20 \cdot 4)$ & $5 \cdot 32$ & 2 & 0.070 \\
\hline Tiredness & $25(13 \cdot 6)$ & $28(20 \cdot 1)$ & $48(17 \cdot 5)$ & 2.55 & 2 & $0 \cdot 279$ \\
\hline Persistent headaches & $23(12 \cdot 5)$ & $19(13 \cdot 7)$ & $58(21 \cdot 2)$ & $7 \cdot 16$ & 2 & 0.028 \\
\hline $\begin{array}{l}\text { Earache } \\
\text { lactes }\end{array}$ & $27(14 \cdot 7)$ & $15(10 \cdot 8)$ & $47(17 \cdot 2)$ & 2.95 & 2 & $0 \cdot 228$ \\
\hline Fever-high temperature & $21(11 \cdot 4)$ & $25(18 \cdot 0)$ & $67(24 \cdot 5)$ & $12 \cdot 30$ & 2 & 0.002 \\
\hline Feeling depressed-unhappy & $20(10 \cdot 9)$ & $25(18 \cdot 0)$ & $42(15 \cdot 3)$ & $3 \cdot 45$ & 2 & $0 \cdot 178$ \\
\hline Temper tantrums & $37(20 \cdot 1)$ & $37(26 \cdot 6)$ & $74(27 \cdot 0)$ & $3 \cdot 13$ & 2 & $0 \cdot 209$ \\
\hline Bedwetting & $41(22 \cdot 3)$ & $29(20 \cdot 9)$ & $64(23 \cdot 4)$ & $0 \cdot 33$ & 2 & 0.846 \\
\hline Poor appetite & $31(16 \cdot 8)$ & $37(26 \cdot 6)$ & $68(24 \cdot 8)$ & $5 \cdot 49$ & 2 & 0.064 \\
\hline Persistent cough & $57(31 \cdot 0)$ & $52(37 \cdot 4)$ & $117(42 \cdot 7)$ & $6 \cdot 45$ & 2 & 0.040 \\
\hline Runny nose & $72(39 \cdot 1)$ & $56(40 \cdot 3)$ & $139(50 \cdot 7)$ & $7 \cdot 43$ & 2 & 0.024 \\
\hline Any symptom & $147(79 \cdot 9)$ & $119(85 \cdot 6)$ & $248(90 \cdot 5)$ & $10 \cdot 41$ & 2 & 0.006 \\
\hline Mean (SD) No of & $3.73(3.95)$ & $4 \cdot 39(4 \cdot 63)$ & $5 \cdot 44(5 \cdot 19)$ & $F=7 \cdot 56$ & 2,594 & $<0.001$ \\
\hline Mean (SD) No of & $2.04(1.98)$ & $2 \cdot 46(2 \cdot 36)$ & $2 \cdot 86(2 \cdot 43)$ & $F=7 \cdot 23$ & 2,594 & $<0.001$ \\
\hline Mean (SD) health evaluation score & $2 \cdot 24(0.89)$ & $2 \cdot 30(0.91)$ & $2 \cdot 41(0.94)$ & $F=1.98$ & 2,592 & $0 \cdot 140$ \\
\hline
\end{tabular}

* Symptom present in any child living in household. during the past two weeks to deal with symptoms and presence of recurrent and long-standing illness. No significant differences were found.

\section{HOUSING CONDITIONS AND CHILDREN'S HEALTH}

Table III shows the prevalence of symptoms among children in the household by housing conditions. Significant differences were found regarding wheezing, sore throat, persistent headache, fever and high temperature, persistent cough, and runny nose. The highest proportion reporting these symptoms was always found in mouldy households; with only one exception (sore throat) the lowest proportion with symptoms was found in the dry households. Not only was there a significant difference in the proportion with any symptom (147 (79.9\%) in dry households, 119 $(85.6 \%)$ in damp houses, $248(90.5 \%)$ in mouldy houses) but the mean number of symptoms (overall and per child) also differed significantly and in the same direction. The mean child health evaluation score was not significantly different between groups (table III).

In our preliminary univariate analyses we had noted that three of the possible confounding variables (overcrowding, any cigarette smoker, nobody employed) were significantly associated with presence or absence of individual symptoms. Another set of logistic regression analyses was therefore undertaken in which the dependent variables were the six symptoms previously shown to be significantly associated with housing conditions. After controlling for these three confounding variables differences remained significant for wheezing, sore throat, persistent headache, fever and high temperature, runny nose, and for any symptom. Only the main effect of housing conditions on cough was no longer significant.

The relation between housing conditions on the one hand and mean number of symptoms and mean health evaluation score on the other was further examined in a series of analyses of covariance. As before, we took into account differences in the length of time at address and other housing problems (or cold alone). We also added a control for the number of children in the household and the adult's general health questionnaire score (included because although it did not differ significantly with housing conditions, it was correlated highly with both the mean number of symptoms in children $(\mathrm{r}=0.30, \mathrm{p}<0.001)$ and mean child evaluation score $(r=0.35, p<0.001))$. Finally, we partialled out the effects of cigarette smoking in the household, unemployment, low income, and overcrowding. There was still a significant effect of housing conditions on the mean number of symptoms $(b$ ranging between $0 \cdot 10$ and $0.13, p<0.02$ to $<0.005$ ). Children living in mouldy households were reported to have the highest number of symptoms and those living in dry households the fewest. Mean child evaluation score remained unrelated to housing conditions.

Table IV shows the dose-response relation between children's symptoms and increasing severity of dampness, mould growth, and air spore concentration. The more serious the dampness the greater the prevalence of bodily aches and pains, wheezing, vomiting, sore throat, irritability, tiredness, persistent headache, fever and high temperature, feeling depressed and unhappy, poor appetite, persistent cough, and runny nose. Dampness was also associated overall with the presence of any symptom. The more severe the mould growth the greater the likelihood of wheezing, sore throat, irritability, persistent headache, fever and high temperature, and runny nose. Mould growth was also associated with the presence of any symptom. The greater the air spore concentration the greater the prevalence of wheezing, irritability, and fever and high temperature. 
TABLE IV-Children's health during past two weeks. Dose-respons relation with damp, mould, and air spore count. Figures are tau $c$ values ( $p$ values) unless stated otherwise

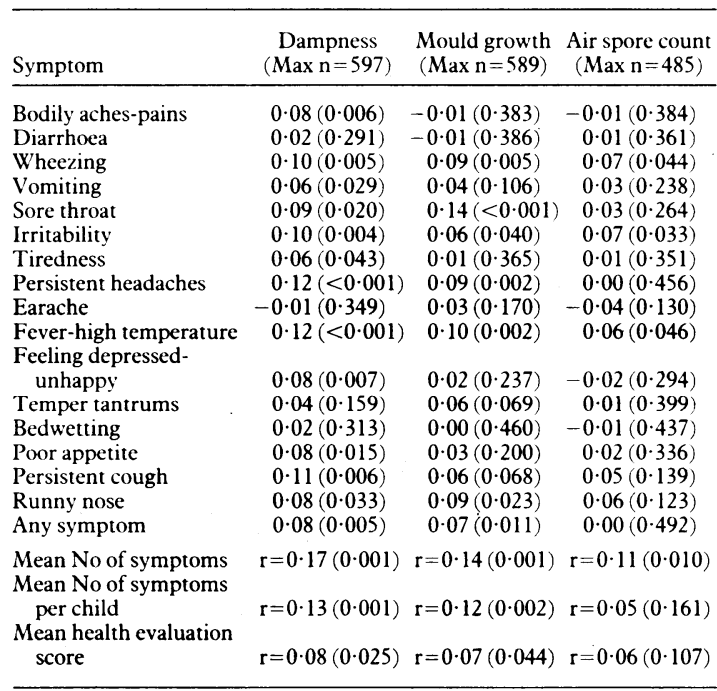

Overall, the mean number of symptoms tended to increase with greater severity of dampness, mould growth, and air spore concentration, whereas the mean number of symptoms per child and the mean child health evaluation score were related only to greater doses of dampness and mould growth. The mean number of symptoms per child and the mean child health evaluation score were unrelated to the extent of air spore concentration.

The three groups of housing conditions were compared regarding the action taken to deal with children's symptoms during the past two weeks and presence of recurrent and longstanding illness. Children in mouldy households were more likely to have been given medicines $(51 \cdot 8 \%)$ than children in damp $(43.2 \%)$ or problem free households $(36 \cdot 4 \%)\left(\chi^{2}=10 \cdot 82, \mathrm{df}=2\right.$, $\mathrm{p}<0.005)$. Other differences did not reach significance.

\section{Discussion}

Before offering an account of the role of damp and mould in the aetiology of symptoms it is necessary to consider four types of bias that may invalidate the assumption of a causal link between housing conditions and ill health-namely, investigator bias, respondent bias, selection bias, and omitted variable bias.

Investigator bias may be dismissed as housing conditions and the health of household members were independently assessed by two different groups of researchers, neither of which included the principal investigators. In addition, questionnaires were coded and data prepared by workers who were not familiar with the objectives of the study.

Some previous investigations of te housing-health relation, particularly those carried out by tenants' groups, have been criticised on the grounds that people living in damp and mouldy houses will be inclined to exaggerate the extent of their own and their children's health problems. A recent study suggested that the observed association between mould and respiratory symptoms may be accounted for by parental awareness of mould in the home. ${ }^{8}$ Our reliance on informants' reports about the health of themselves and their children was deliberate. We were unconvinced about the reliability and appropriateness of diagnostic data derived from official records, especially those of general practitioners. We thought that it was valid to assess health state by means of self reported symptoms while at the same time recognising that the likelihood of respondent bias was thereby increased. This problem was minimised, however, by the use of independent, expert assessments of housing conditions. Although subjective (self reported) and objective (expert) evaluations of the presence of damp and mould were significantly and positively associated $(\mathrm{k}=0.26, \mathrm{p}<0.001)$, there was disagreement about damp and mould state in $183(30 \cdot 7 \%)$ of the dwellings. Furthermore, respondents could not have been aware of the air spore concentration in the building. (The association between self reported damp mould and spore count, although significant, was not high: $\mathrm{r}=0 \cdot 14, \mathrm{p}<0.001$.) Nevertheless, symptoms in both children and respondents were related to this measure. We also included the general health questionnaire score as a covariate when examining the effect of housing conditions among children as respondents with greater levels of psychological distress tended to report more ill health. The mean number of symptoms remained significantly higher in damp and mouldy dwellings than in dry dwellings. Thus though the overall number of symptoms may have been higher than would be obtained by an independent observer, there is no reason to believe that such a bias affected the main findings.

Another possible source of error is that of selection bias. People who already suffer from ill health may tend to live in damp or mouldy dwellings: symptoms may exist before, rather than be a consequence of, living in poor housing conditions. This could happen, for example, where the least desirable dwellings were allocated to those most in need who, by virtue of low income, social circumstances, or medical history, were more likely to report ill health. Although housing departments may not always act impartially in the selection of tenants to households, there is no evidence to suggest that they systematically allocate families in poorer health to damp and mouldy households. In this study families in damp and mouldy dwellings were not more likely to have come from previously poor conditions or to have moved for health reasons or to have lived a shorter period of time in the dwelling than families in dry houses. In addition, many of the children in all three housing groups were born in the household in which they were currently living. Thus selection bias is highly unlikely to account for the findings.

Omitted variable bias can arise when variables that are correlated with the major independent variable (in this case housing conditions) and have a significant (possibly causal) relation with the dependent (outcome) variable (such as symptom score) are excluded from the analysis. Whereas several factors were significantly associated with health state, only cold was also associated with housing conditions. Cold stress may have made some contribution to the experience of symptoms: a damp house is usually a cold house. Unfortunately, we were unable to assess the temperature of dwellings. We did, however, gather information on perceived coldness of the dwelling and this variable was included in the covariance analysis.

In summary, adult respondents living in damp and mouldy dwellings were more likely to report nausea, vomiting, constipation, blocked nose, breathlessness, backache, aching joints, fainting, and bad nerves than respondents living in dry dwellings. These differences remained after controlling for the respondent's economic position and cigarette smoking. In a more extensive covariance analysis respondents living in mouldy dwellings were found to have the highest number of symptoms even after taking account of possible confounding factors such as length of time at address, other housing problems, household income, economic position, and cigarette smoking. This analysis, however, showed that the respondent's subjective evaluation of health and psychological distress 
were both unrelated to housing conditions. Increasing doses of dampness and mould were especially linked to nausea, blocked nose, breathlessness, high blood pressure, and bad nerves and to a greater number of symptoms and a poorer health evaluation score.

For children, living in damp and mouldy dwellings was associated with a greater prevalence of wheeze, sore throat, runny nose, cough, headaches, and fever compared with those living in dry dwellings. With the exception of cough these differences were unaffected by the introduction of controls for smoking in the household, employment, and overcrowding. Additional possible confounding variables were added in an analysis of covariance, which still showed a significant effect of housing conditions on the mean number of symptoms among children in the household. A doseresponse relation was particularly noted with respect to wheeze, sore throat, runny nose, irritability, persistent headache, and fever and high temperature. Increasing severity of dampness and mould and any symptom, the mean number of symptoms (overall and per child), and the mean child health evaluation score were also associated.

Several studies have suggested that some varieties of fungal spores are allergenic and give rise to respiratory conditions. Burr et al identified Penicillium notatum, Cladosporium herbarum, and Aspergillus species in the homes of asthmatic patients and found that the moulds gave positive skin test reactions for allergy. ${ }^{9}$ Fungal spores are also believed to affect the respiratory tract by producing tissue lesions, by forming saprophytic colonies on mucus plugs, and by causing inflammation and irritation of nasal and bronchial passages and the alveoli. ${ }^{31011}$

An investigation by May et al found symptoms of fever, muscular pain, chest tightness, cough, and headache to be directly caused by organic toxic dust and suggested that this "pulmonary mycotoxicosis" may represent a systemic reaction to inhaled fungal toxins. ${ }^{12}$ Although their study was concerned with acute episodes after exposure to massive doses of organic dust, possibly similar, though less severe, symptoms occur as a chronic response to prolonged exposure to low concentrations of fungal toxins.

Analysis of the moulds collected from the dwellings in our study is still proceeding and a supplementary report on the relation of specific moulds to symptoms will be prepared. Single dwellings in the study were found to be harbouring over 15 species of mould and probably some of these would give rise to allergenic or toxic reactions, or both.

Emotional symptoms in children such as irritability and unhappiness are probably linked to physical symptoms and indicate that the mental health of children is also at risk. Some of the adults' symptoms are difficult to explain by reference to mould, though aching joints and nausea could both be reactions to fungal toxins. Reports of "bad nerves" are not surprising where living areas are unpleasant, children are sick, and family life may be fraught. Backache and constipation are puzzling phenomena and may be indirect consequences of conditions in the home. Breathlessness and blocked nose may be more closely related to low temperature. Increased blood pressure and hypoxia have been observed as reactions to cold stress. ${ }^{13}$
We have attempted at all stages of this study, which is probably the largest of its kind ever undertaken, to refute the null hypothesis-namely, that there is no relation between housing conditions and health state. To that end, we adopted double-blind interviewing procedures, included a wide array of possible confounding factors, and used multivariate statistical techniques. Having eliminated (as far as possible) alternative explanations for our findings, we concluded that damp and mouldy dwellings have direct deleterious effects on the physical and psychological wellbeing of adults and children. Our confidence in this conclusion is enhanced in more positive fashion by two observations: firstly, the similarity of these findings with those reported in our earlier study, ${ }^{\prime}$ especially concerning children's respiratory symptoms; and, secondly, the strong relation between increasing doses of adverse housing conditions (dampness, mould growth, and air spore concentration) and symptoms of ill health, which is unlikely to be the result of respondent bias.

A considerable body of evidence now exists that supports the contention that dampness and mould is an important public health issue, not solely for its immediate impact but also for the longterm implications. Poor housing conditions in childhood, for example, are associated with higher rates of admission to hospital and higher morbidity and mortality in adult life.$^{1+15}$ Hopefully, planners, policy makers, and medical practitioners will now plan concerted joint action to eradicate this unacceptable and needless health risk.

This study was supported by grants from Glasgow and Edinburgh district councils and the London Research Centre. Many associations and people have contributed to this research. In particular, we acknowledge advice and practical assistance from the Community Health Resource Unit, Glasgow; Easthall Residents' Association; Royston, Molendinar community councils, and the Technical Services Agency, Glasgow.

1 Martin CJ, Platt SD, Hunt SM. Housing conditions and ill health. $B r$ Med $\mathcal{f}$ 1987;294:1125-7.

2 Institute of Environmental Health Officers. Mould fungal spores - their effects on health and the control, prevention and treatment of mould growth in dwellings. London: IEHO, 1985.

3 Gravesen S. Fungi as a cause of allergic disease. Allergy 1979;34:135-54.

4 Larsen LS. A three year survey of microfungi in the air of Copenhagen 1977-1979. Allergy 1981;36:15-22.

5 Goldberg DP. The detection of psychiatric illness by questionnaire. London: Goldberg DP. The detection of
Oxford University Press, 1972.

6 Baker RJ, Nelder JA. The GLIM system manual. Release 3. Oxford: Numerical Algorithms Group, 1978.

7 SPSS. SPSS-X user's guide. New York: McGraw-Hill, 1983.

8 Strachan DP. Damp housing and childhood asthma: validation of reporting of symptoms. Br Med f 1988;297:1123-6.

9 Burr ML, Mullins J, Merret TG, Scott NC. Indoor moulds and asthma. $\mathcal{F}$ Roy Soc Health 1988;3:99-101.

10 Hosen H. Moulds in allergy. Fournal of Asthma Research 1978;15:151-6.

11 Maunsell $\mathrm{K}$. Sensitisation risk from inhalation of fungal spores. $\mathcal{F}$ Laryngol Otol 1954;68:765-75.

12 May JJ, Stallones L, Darrow D, Pratt DS. Organic dust toxicity (pulmonary mycotoxicosis) associated with silo unloading. Thorax 1986;41:919-23.

13 Lloyd E. Cold stress and ischaemic heart disease. Radical Community Medicine 1987;30:9-11.

14 Folmer-Anderson T. Persistence of social and health problems in the welfare state: a Danish cohort experience from 1948 to 1979 . Soc Sci Med state: a Danish
1984;18:555-60.

15 Britten N, Davies JMC, Colley JRT. Early respiratory experience and subsequent cough and peak expiratory flow rate in 36 year old men and women. Br Med J 1987;294:1317-20.

(Accepted 29 April 1989) 